\title{
An Integrative Socio-Technical Enterprise Approach to Urban Design/Planning for Sustainable Development
}

\author{
Timothy J. Downs \\ International Development, Community and Environment Department (IDCE), Clark University, Worcester, USA \\ Email: tdowns@clarku.edu
}

How to cite this paper: Downs, T.J. (2018) An Integrative Socio-Technical Enterprise Approach to Urban Design/Planning for Sustainable Development. Open Journal of Civil Engineering, 8, 183-204. https://doi.org/10.4236/ojce.2018.82015

Received: February 21, 2018

Accepted: June 18, 2018

Published: June 21, 2018

Copyright $\odot 2018$ by author and Scientific Research Publishing Inc. This work is licensed under the Creative Commons Attribution International License (CC BY 4.0).

http://creativecommons.org/licenses/by/4.0/

\section{cc (i) Open Access}

\begin{abstract}
Human society locally and globally needs to better understand and respond to ever-more complex, interwoven problems: environmental degradation; climate instability; persistent poverty; disparities in human health; growing income/wealth inequality; economies and infrastructures vulnerable to climate shock; and mounting socio-political unrest. Cities are where most people live, urbanization is a strong upward global trend, and cities bring all these problems into sharp, compelling focus. Since outcomes stem from processes and systems, we argue transformative changes depend on re-imagining the $\underline{\text { rrban }}$ Design, Urban Planning and Urban Development Practice (UD/UP/UDP) process. While there has been insufficient attention to process innovationwith technological aspects tending to dominate UD/UP/UDP work-emerging systems views of cities, and disenchantment with existing modes are enabling. We propose an empirically based integrative frame to tackle recognized conundrums, and inform an adaptive UD/UP/UDP process-from concept through design, assessment, planning, implementation, project functioning and monitoring. The frame contemplates six domains (6-D): 1) Project ethos, concept, and framing; 2) sectors, topics, and issues; 3) Varying spatial and temporal scales; 4) Stakeholder interests, relationships and capacities; 5) Knowledge types, modes and methods; and 6) Socio-technical capacities and networks. The frame, process and outcomes constitute a socio-technical enterprise (STE) approach to UD/UP/UDP work, with implications for education, training, and professional practice. We highlight the pivotal role Integrators and Universities play, and the scalability of STE knowledge/capacity networks. The case of Greater Mexico City/Central Mexico Urban Region illustrates the utility of the approach in a hyper-complex, climate-change vulnerable regional context.
\end{abstract}




\section{Keywords}

Sustainable Development, Integrative Approach, Capacity Building, Mexico City

\section{Introduction}

\subsection{Global Context}

In 2007, the world passed a singular threshold: for the first time in human history more people lived in urban areas than rural ones [1] —and the trend has continued strongly in an upward direction. In the aggregate most of this growth is happening in "mid-sized cities" in the so-called "developing world" [1], although very large cities-mega cities ( $>10$ million inhabitants) and very large urban agglomerations like Cairo, Tokyo, Los Angeles and Mexico City-continue to present the most serious challenges to social, economic and environmental sustainability, while testing the viability of traditional approaches to urban design and providing strong incentives to innovate. Among the signs most cities are moving away from sustainability are indicators of declines and inequities in social justice, economic justice and environmental justice, and those related to weak climate-change resilience. In 2014, the $5^{\text {th }}$ IPCC Assessment Report (AR5) stated: "Climate change is a threat to sustainable development. Nonetheless, there are many opportunities to link mitigation, adaptation and the pursuit of other societal objectives through integrated responses. Successful implementation relies on relevant tools, suitable governance structures and enhanced capacity to respond" ([2], p. 94).

Almost 30 years after "Our Common Future" first presented the sustainable development paradigm to the world [3], 2016 saw a critical review of societal progress-and lack thereof-with the United Nations publication of "Sustainable Development in the $21^{\text {st }}$ Century" (SD21 Project) [4]. It states: "[A] new political deal is needed, which provides a clear vision and way forward for the international community, national governments, the private sector, civil society and other stakeholders for advancing the sustainable development agenda in an integrated manner" ([4], p. iii). These high-level multi-lateral perspectives are themselves inescapably political, but they do endorse an integrative approach and the need for public agencies and civil society groups to engage constructively with each other. However, they fail to call out critical foundational conceptual and practical difficulties, conundrums and gaps in societal capacity that undermine success (see discussion of Millennium Village Project in [5] [6]).

\subsection{Urban Design Context}

The history of Urban Design reveals ample room for creative, multi-perspective integrative thought. Krieger [7] notes that the most influential "designers" have 
come from a variety of other fields and persuasions: Architecture (Le Corbusier); Landscape Architecture (Olmsted, also a social activist); and Economics. Krieger ([7], p. 1) -from the vantage point of Harvard University's renowned Graduate School of Design-states that urban designers enjoy a special commitment/mandate: "[Urban Designers] realize that to renew the centers of cities, build new cities, restore the parts of old cities worthy of preservation, and construct equitable growth management programs on the periphery require vastly different strategies, theories and design actions. Indeed one may rejoice that there are many spheres of urbanistic action..."

Interestingly, in contrast to expanding cities in the so-called "developing world", cities in the "developed world" are grappling with de-population as a driver of shrinking cities. In relation to scale and size, the term "rightsizing" is being used to re-consider spatial scale and extent of urban infrastructure, in the context of the New Urbanism and Landscape Urbanism paradigms [8]. Questions that emerge are relevant to urban sustainability generally: What physical form and size should the city take...? What decisions should city officials make, concerning which aspects of the city should survive and who should live where? How much would rightsizing cost, and who would pay? Does an ultimate vision of the city guide rightsizing, or will policymakers simply follow immediate imperatives? [8].

Writing on urban revitalization and historic preservation, Ryberg-Webster

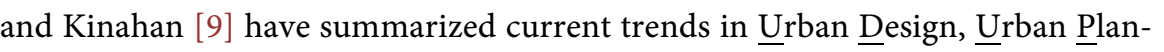
ning and $\underline{\text { Urban }}$ Development Practice (UD/UP/UDP) in the US context. Four perspectives have emerged: 1) the "New American City;" 2) place matters in economic and community development; 3 ) the role of anchor institutions; and 4) legacy cities. Transformations of old urban downtown areas into vibrant live-work-play areas have been explored since the late 1990s [10]-[16]. Urban Planners are working to create more sustainable urban cores with a strong sense of place by reclaiming brown fields, converting old public housing to mixed-income residential, investing in green spaces, protecting historic resources, and revising zoning policy [17] [18] [19] [20]. Re-imagined US downtown cores have diverse businesses, "anchor institutions" (like universities), and multi-stakeholder engagement by community groups, policy makers, businesses and real-estate professionals [20] [21]. Integrative thinking is therefore not new, but it is evolving to meet pressing challenges.

\subsection{Problem Formulation}

With this backdrop, it is not surprising that rapidly developing cities-where political power and sustainability challenges are concentrated-exemplify systemic weaknesses and obstacles very well, with great urgency. How does society tend to respond? The closely connected fields of UD/UP/UDP are situated at the heart of these issues, and two main responses dominate: 1) the business-as-usual (BAU) approach, including education, professional training and project designs 
that tend to be centered on conventional urban paradigms, technology and infrastructure, minimally integrative, and marginally innovative; and 2) the technological-innovation approach that considers that "technology" holds the key to more sustainable, climate-resilient cities.

The latter is represented, for example by those advocating for resilient "smart cities" based on computerized systems and Information Technology (IT, see [22] for example). Indeed, many public and private sector interests converge on the smart-city model, and opportunities to retrofit many urban systems (especially energy, telecommunications, and transit) to be "smarter". This momentum and enthusiasm is also understandable given society's tendency to over-rely on technological fixes, and growing investment in Artificial Intelligence and Robotics (AI\&R). Technology advocates acknowledge "there is certainly no one-sizefits-all model according to which life in the city of the future will work" [22]. A "developed-country" bias is often present: "Many interesting solutions and approaches are already in place to address the most pressing challenges" [22]. While it is arguable this is so in the "developed world", it is far from the case in the rapidly developing or mushrooming cities of the "developing world".

There are four main problems with conventional approaches: 1) BAU, by definition, has led us down a path away from sustainability, and marginal tweaks will not help us change course; 2) over-reliance on technology alone to the exclusion of other dimensions-especially social and socio-technical innovations-is one of the hallmarks of BAU approaches to development projects, programs and practice (including but not limited to UD/UP/UDP) in both developed and developing countries; 3 ) outcomes desired by a powerful minority tend to drive the UD/UP/UDP process-reinforcing inequities and socio-economic injustices-rather than a more balanced socio-technical innovation process driving outcomes; and 4) existing approaches pay insufficient attention to the socio-technical capacity building needed-integral to urban sustainability-to design and deploy adaptive systems able to respond to social, economic and ecological/climatic instabilities.

\subsection{Objective}

The objective of the paper is to apply an empirically based integrative frame comprising six domains (6-D) to reconsider UD/UP/UDP in light of sustainability conundrums, challenges and opportunities: It seeks to show that a 6-D perspective helps to illuminate gaps in concepts, processes, outcomes and capacities, and suggests ways to fill them and strengthen collective capacity to understand and respond to pressing $21^{\text {st }}$ century urban/regional issues. In this context, the pivotal role played by a new, envisioned cohort of professional UD/UP/UDP integrators is highlighted, and the role of the University as educator/trainer, but also catalyst. We use the context of Mexico City and the Central Mexico Urban Landscape it dominates as a compelling case study to illustrate the utility of this approach under hyper-complexity. 


\section{Conundrums in Urban Settings}

In previous work three major conundrums for sustainable development practice were identified that can be applied to UD/UP/UDP work [6]: 1) Socio-ecological complexity conundrum; 2) Varying spatial/temporal scales conundrum; and 3) Stakeholder diversity conundrum. In response to these conundrums, the 6-D integrative frame was developed.

\subsection{Socio-Ecological Complexity Conundrum}

Dynamic socio-ecological systems are intrinsically complex comprising multiple components linked together with strong feedback loops. While more complexity in descriptions, analyses and models may represent reality better, it may be confusing to managers, communities, and policy makers, and poses high demands on data gathering. Einstein's principle [23] provides some guidance: "A scientific theory [model] should be as simple as possible, but no simpler." We confront the question: How can essential elements of an urban/regional system be modeled and presented simply enough to be accessible and useful to diverse stakeholders, without over simplifying and losing validity?

\subsection{Varying Spatial/Temporal Scales Conundrum}

Spatial scale poses a fundamental challenge to urban/regional projects: How can urban development operate at an appropriately large scale (as revealed by 2.1), while remaining responsive at smaller scales? This aspect is one of the most transformative both conceptually and operationally (see Mexico City/Central Mexico Urban Region case below) because it radically changes the basic reference frame for design (e.g. several inter-connected cities vs. just one city on its own). On the temporal side, individual projects tend to use one timeframe-e.g. 30-year design life for a power station, 5 - 10 years for neighborhood re-vitalization-while social and ecological cycles of change may be happening over much shorter timeframes, exacerbated by climate instability. Sustainable development has challenged traditional planning horizons by calling for the consideration of generational timeframes: 25 - 50 - 100 years ahead, with attendant uncertainties. How can we attend to urgent short-term and related long-term goals, while adapting to changing needs and conditions?

\subsection{Stakeholder Diversity Conundrum}

Socio-ecological systems at varying scales comprise diverse stakeholders, and urban/regional development projects impact them in positive, negative, and inequitable ways. How can urban projects reduce impact inequities, mitigate negative impacts, be responsive to stakeholder diversity, and leverage this diversity to build stronger societal capacity?

\section{Integrative Frame}

The integrative framework applied herein for identifying and addressing gaps 
and shortcomings in conventional UD/UP/UDP work is a critical synthesis published in 2017 [6]. It draws on empirical evidence (see [4] [24] [25] [26], five IPCC Assessment Reports (since 1990, incl. [2]), experiences with two global environmental assessments (Millennium Ecosystem Assessment and GEO-4), as well as climate change policy experience [27] [28], and the author's experiential knowledge. The framework consists of six domains (6-D): 1) Project ethos, concept, and framing; 2) sectors, topics, and issues; 3) Varying spatial and temporal scales; 4) Stakeholder interests, relationships and capacities; 5) Knowledge types, modes and methods; and 6) Socio-technical capacities and networks.

\subsection{Domain 1) Project Ethos, Concept, and Framing}

Identifying and addressing gaps and flaws in UD/UP/UDP have a logical beginning in project conception, framing, and early design-making it the most important stage for innovation. Business-as-usual (BAU) projects tend to be top-down, driven by powerful actors in government, donors and knowledge/technology elites, exhibiting scant engagement with civil society stakeholders (and groups representing the interests of non-human species). Under- or mis-represented civil society groups have arguably most to win or lose in urban design and development, yet typically constitute the majority of people in a given setting. As a structural matter, the financial and technical resources typically mobilized for urban projects create incentives that too often eclipse the concerns and interests of less powerful stakeholders, especially marginalized communities and/or those representing biodiversity/ecosystems. Compounding the bias, community concerns and indigenous, local knowledge are devalued compared to dominant scientific-technical framings of development [29] [30] [31]. Thus, the BAU approach to urban design and the common IT-based "smart" alternative (see 1.3) both emphasize technological processes and outcomes to the exclusion of social/socio-technical ones, and it is this imbalance and bias that impedes sustainable development in urban, peri-urban and rural settings ${ }^{1}$ (see, for example, [32] [33] [34] [35]. The 6-D Framework as a whole responds to this imbalance by actively integrating social and technical aspects of innovation, and by conceiving, framing and designing UD/UP/UDP work as a socio-technical enterprise. This thinking is supported by a growing literature in the fields of socio-technical transitions [36] and sustainability science [37].

Conceiving, framing and designing UD/UP/UDP work in new, integrative ways goes well beyond conventional project design (design team meeting a design brief by producing a project design). It requires a deep breath, long step back and thoughtful consideration of the design process itself, and the whole project continuum: 1) Concept and Design-aims, approach and framing; 2) Assessment-characterizing baseline conditions to inform planning; 3) Planning

${ }^{1}$ It is also necessary to think beyond the terms "urban", "peri-urban" and "rural" to recognize the continuum of the socio-ecological setting in which towns and cities are situated, and inter-dependencies therein (see also Domain 5: Spatial and Temporal Scales). 
- comparing alternative ways to meet needs/solve problems (using projected impacts/tradeoffs, as in improved EIA [38]) and/or co-visioning desired futures and pathways to get there; 4) Implementation of the chosen alternative/pathway in the given setting(s); and 5) Monitoring-keeping track of the activities of the project, its actual impacts, and how conditions are changing. This familiar sequence needs to be re-cast, however, as an adaptive process monitoring of each stage, as well as monitoring of changing conditions, enjoy feedbacks to inform adaptations at each stage (Figure 1 ).

\subsection{Domain 2) Sectors, Topics, and Issues}

Integration across multiple sectors, topics and issues-e.g. water supply and sanitation (WATSAN), energy systems, public health, food systems, housing, the economy, climate resilience, social justice-forms the second major domain for UD/UP/UDP work. Sectors and issues are strongly interrelated in terms of stocks and flows of five different types of capital: natural; human; social; financial; and manufactured. As such, they comprise complex ecological, social, economic, cultural, political, and technological (ESECPT) systems. Logically therefore, urban development alternatives/scenarios need to be compared using sustainability criteria and environmental (and social) impacts assessment (EIA) processes that encompass indicators of ESECPT impacts. Judged by these criteria/impacts, the deliberative process can consider tradeoffs among impacts, and determine which of the alternatives is the most sustainable. For a discussion of how EIA can be transformed to support sustainable development and poverty

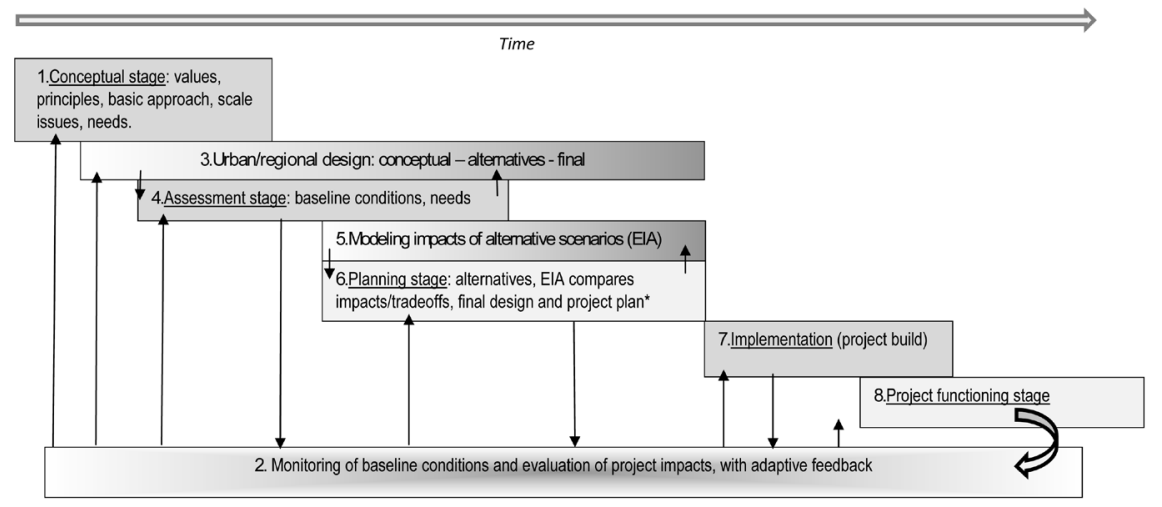

Figure 1. Stages and key activities of a project, with adaptive feedback. Familiar operational stages are enhanced by interactions and information exchanges (arrows). Extended, ongoing monitoring activity (Stage \#2) continues to build shared information /knowledge resources (capacity level \#3, Domain \#5, see 3.5 and Figure 2) about changing conditions, needs, and impacts over time. Stage \#3-Design-is defining for any project, shaped by guiding sustainability/climate resilience values and concepts (Stage \#1, Domain \#1, see 3.1), and made responsive by information exchanges. Stage \#5-Modeling-is also integral to projecting the impacts of climate scenarios and comparing the impacts/resilience of alternative development pathways. These impact criteria reflect sustainability principles, are key indicators for ongoing monitoring (\#2), and inform our choice of the most sustainable/climate-resilient pathway (enhanced EIA methodology, see [38]). 
reduction see Downs [38]. Informed by Domain 1, concepts for an urban project's scope will strongly shape its design. A practical and strategic way to tackle multi-sector work by engaging multiple stakeholders (Domain 3) is to identify gateway sectors - sectors that offer a way-in to the complex reality of socio-ecological systems. As we will see below in the Mexico City case, WATSAN remains a potent gateway sector for advancing sustainability. We can also identify keystone sectors (e.g. water, energy) that serve to simplify urban/regional complexity by virtue of their governing influences on multiple sectors. Downs [26] called out water as the sector with the highest degree of connectivity to the other 17 topics in the 1992 Agenda 21: Blueprint for Sustainable Development.

Besides the practical advantage of a multi-sectoral approach to urban/regional development, using gateway and/or keystone sectors, resilience theory and "resilience thinking" [28] [39] provide a compelling rationale: multi-sectoral design and planning allows for systems-level resilience to be built-in to the UD/UP/UDP project so that it can buffer shocks and recover from them. Indeed, climate-change resilience and impact mitigation are now central to sustainable development; resilience indicators are among the most important impact indicators to be considered during conceptual, assessment (incl. EIA) and planning stages (Figure 1). Climate change is the ultimate leveler, the meta-issue that affects all others, and all stakeholders. Thus, alongside gateway and keystone sectors, it can drive meaningful, open stakeholder dialogue and requisite levels of appropriate stakeholder engagement with all stages of a project, from inception through adaptive monitoring (Figure 1).

\subsection{Domain 3) Spatial and Temporal Scales}

As the Mexico City/Central Mexico Urban Region case will show below, the spatial scale used to consider UD/UP/UDP work is one of the most significant aspects of innovation that shapes a project. Particularly in the context of a climate-changing world, and a world where water scarcity is a stark priority (see, for example the Cape Town water crisis [40]), urban professionals need to be considering overlapping spatial scales in their designs: local, watershed, multi-watershed, regional, and national. This is the equivalent of zooming-in and out of a satellite image of the Earth's surface to recognize landscapes and cityscapes that are part of a biophysical continuum, with interdependencies and multiple connecting flows of natural, human, social, financial and manufactured capital. Stated another way: the sustainability/resilience of a given city depends on the sustainability of its constituent parts (e.g. municipalities in the mega-city context or neighborhoods in a smaller city or town), and the sustainability of the larger geographical/hydrological region of which it is a part. Cities that share water resources, or that exchange goods and services in a regional economy (including food and energy), are co-dependent, and the regional scale must therefore be considered in any designs of those cities. 
In a similar vein, the time scales used for design and planning are several, and need to be considered together: 1) short-term activities of an urban project to address urgent, easy-to-reach priorities ( 0 - 10 years, e.g. building new neighborhood health clinics to meet needs, providing safe water, upgrades to make wastewater sanitation adequate); 2) mid-term activities (0 - 20 years, e.g. making sanitation adaptive and resilient to climate shock, including power outages, making new infrastructure like roads and bridges and tunnels climate resilient; and iii) longer-term efforts to build and/or rebuild cities and their regions as sustainable socio-technical/economic entities (0 - 20 - 50 - 100 years). It is helpful for UD/UP/UDP professionals to keep in mind that different stakeholders think, feel, plan and act using very different time scales: local politicians may operate primarily on a 3-year election cycle, with the short-term view resonant; businesses may worry about weekly shifts in stock price while at the same time thinking strategically about medium- and long-term profitability/viability; and sustainability advocates and IPCC scientists and policymakers consider time scales from 0 - 100 years out (IPCC scenarios are projections by models out to the 2100 planning horizon and beyond, [2]). In practice, therefore, successful UD/UP/UDP based on the socio-technical enterprise model will simultaneously design, plan and deploy activities that meet short-, medium- and long-term interests, concerns and needs in ways they intersect.

The other basic reason that it is important for professionals to consider multiple, overlapping spatial and temporal scales is that socio-ecological systemsalso called coupled human-environment systems ${ }^{2}$-and their constituent social and ecological components are spatially and temporally dynamic. Put another

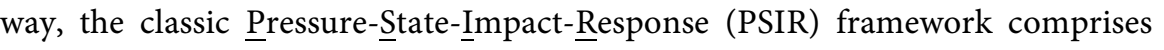
parameters that enjoy variability at multiple overlapping spatial and temporal scales. Pressures like population growth and resource consumption may be happening at a regional, national and/or global scales, while changes in state (e.g. air pollution) and impacts (e.g. high rates of respiratory illness and associated premature death) are being felt at multiple spatial and temporal scales. Note: While changes in state and impacts manifest at multiple scales, they are not felt evenly. Indeed, one of the main technical failures in conventional EIA practice that needs to be addressed by an integrative 6-D approach is the consideration during conceptualization, assessment and planning stages (Figure 1) that impactsboth positive and negative-are unevenly distributed across a landscape and a population [6]. These phenomena raise fundamental questions about the social, economic and environmental justice of development projects, issues at the core of sustainable development: intra-generational and inter-generational equity are guiding sustainability principles. Modeling the spatial patterns of impacts expected from a development alternative, and the BAU default, calls strongly for

${ }^{2}$ At the author's institution, Clark University, a landmark symposium occurred in 1987: "Earth as Transformed by Human Action" [41], which helped launch the fields of Global Environmental Change (GEC), Land Use/Land Cover Change, and Sustainability Science. 
Geographic Information Science/Geographic Information Systems/Remote Sensing (GI-Science/GIS/RS), as-yet under-utilized in conventional EIA and $\mathrm{UD} / \mathrm{UP} / \mathrm{UDP}$ work.

\subsection{Domain 4) Stakeholder Interests, Relationships and Capacities}

At the core of a socio-technical enterprise approach to sustainable UD/UP/UDP work is human and social capital: the diverse array of social actors and stakeholders, recognizing that relationships and exchanges among them govern success [6] [25]. This domain both informs, and is a function of, conceptual design ethos (3.1), topical scope (3.2), and scale (3.3). The diversity of stakeholders is also a key source of enabling knowledge (Domain 5) that allows us to better define, understand and respond to complex issues and problems (see, for example, how indigenous livelihoods knowledge enables farmers in Mali to navigate complex agro-climatic systems in [42]). Integrating assets and capacities across stakeholders is thus the engine of the socio-technical approach (Domain 6), providing the capital to define problems and achieve solutions [6] [43]. Unless hu$\mathrm{man} /$ social capital is given prominence-with the social innovation driving the technological innovation instead of the reverse-the institutional incentives for BAU project design and deployment keep them top-down, "expert-driven"3 and technocentric (Domain 1).

Participatory development began as a response to top-down convention in the 1980s (see, for example, [44] [45] [46]). However, these have been insufficient to counter the incentives for top-down development [32] [47] [48] [49] [50] [51]. Calls for top-down-meets-bottom-up approaches are growing: collaborative multi-stakeholder processes [4] [6] [26] [27], many others. Such processes allow the needs, alternative project responses, impact criteria by which they are compared, and enabling capacities to be co-generated among stakeholders.

Since power dynamics among social actors govern development processes and outcomes, a key part of understanding baseline conditions in a given setting is the power dynamics among stakeholders [32] [43]. Fields like political ecology, political economy, human ecology, sociology, anthropology, social geography and political science can illuminate the political and policy system-a pre-requisite for influencing the same. Highly un-even distributions of power are typically the norm, and the failures of many BAU development projects erode trust between the target "beneficiaries" of these projects (civil society at large), and those who design and deploy them, often powerful elites and donors. Interestingly, growing instabilities in the world-ecological/climatic, as well as economic and socio-political-are challenging BAU modes as never before. To be responsive to unstable, uncertain conditions requires adaptive modes at a so${ }^{3}$ A useful re-visiting of the notion of the "expert" is that indigenous people with generations of lived experience are most expert in understanding and responding to conditions in a given setting. They can be supported by others with expertise derived from disciplinary education in social science, natural science, engineering or humanities, and experts with specific professional training. Collectively, knowledge/capacity is grown to meet project needs. 
cietal scale. While there is much that has written about adaptive management e.g. [52] [53] [54], its application to complex UD/UP/UDP projects has been limited.

The fragility of trust and legitimacy among stakeholders in uneven power regimes has been discussed in the context of risks and risk management [55] [56] [57]. In the face of fragility, trust building depends on: 1) efforts made to listen to stakeholder concerns, and responding to them in tangible ways; 2) dialogue that opens up spaces for constructive, respectful exchange; and 3) commitment to building a vibrant sense of shared project ownership, shared responsibility, and shared benefits that outweigh costs [25] [26].

\subsection{Domain 5) Knowledge Types, Modes and Methods}

The "beating heart" of a successful socio-technical enterprise approach to UD/UP/UDP work is a shared knowledge resource comprising indigenous knowledge, multi-, inter-, and trans-disciplinary knowledge, and professional knowledge: a knowledge partnership. The need to incorporate local knowledge in sustainable development work is a growing theme [58] [59].

Epistemological, educational and cultural trends have long shown that specialization naturally arises in a particular field (e.g. Engineering, Law, Medicine, Economics), with specialist training, theories, practices, models, methods, attitudes, behaviors, terminology, tools and ways of framing the issues it tackles. Fields tend to dominate specific issues to the exclusion of others-for example Neo-liberal Market-based Economics dominating Development Policy (to the exclusion of other views from Human Ecology, for example), Bio-Medical models of diagnosis and treatment dominating the Health sector (eclipsing Bio-Social Science and Public Health), and the Technology-based ethos dominating UD/UP/UDP.

The problems with specialization and non-participatory knowledge practices in the context of real-world, multi-faceted UD/UP/UDP work stem from two roots: 1) their inherent limitations in detection and response power in the face of complexity; and 2) their exclusion of alternative perspectives, modes, knowledge and ways of knowing in order to garner power and hegemony. Three major gaps persist in UD/UP/UDP work: 1) weak or missing social science knowledge; 2) weak or missing local knowledge; and 3) weak integration among scientific disciplines and knowledge types [4] [25] [26] [27]. The socio-technical enterprise approach is a direct response to these problems because it mobilizes human and social capital together as the main driver of progress towards sustainability, and it disrupts cultural norms that silo knowledge and capacity, seeking instead to create multi-faceted knowledge, education and capacity as a shared societal-scale enterprise (Domain 6).

\subsection{Domain 6) Socio-Technical Capacities}

The previous five domains are enabled by, and coalesce to form, a sixth domain which recognizes that existing social and technical capacities can be mobilized, 
and new ones created to allow alternative development pathways to be explored and pursued. Using a pragmatic lens, society's ability to understand and respond to complex urban problems-and to vision and pursue a more sustainable development pathway-has been previously argued to empirically depend on integration across six levels of capacity [6] [25] [26]:1) political and financial seed capital to initiate and catalyze projects; 2) human resources, education and training, awareness-raising; 3) shared information and knowledge resources (Domain 5); 4) policy making, decision making and governance (incl. laws, regulations, incentives); 5) appropriate technologies and infrastructure; and 6) enterprise development, especially the stimulation of local/regional sources of entrepreneurship, products and services able to function in a rapidly globalizing economy.

Extending the logic, UD/UP/UDP work is a function of this capacity, but rather than be limited by existing capacity, there is an opportunity to innovate strongly on UD/UP/UDP projects by building new capacities (or enhancing others) to support more sustainable outcomes. Fundamentally, this socio-technical enterprise (STE) becomes the engine of urban innovation. Each stakeholder partner contributes knowledge/capacity to the whole, and receives tangible benefits from its creation. In the UD/UP/UDP context, and for each of its constituent sectors, each of the six levels can be further broken down into discrete operational pieces (Table 1 ).

\section{Key UD/UP/UDP Innovations}

\subsection{Knowledge/Capacity Networks}

The six capacity building levels are to be considered across sectors (Domain 2), not isolated for each sector, such that vibrant functional and organizational linkages arise, alongside attractive economies of scale (Figure 2). The third levelshared information and knowledge resources-lies at the core of the STE because information flows, exchanges, integration and communication are the lifeblood of any knowledge/capacity building network. Adding considerably to its power, STEs can be designed and deployed for a given setting at a given geographical scale, then linked through information flows across settings and scales (Figure 2). In this way, STE responds well to the persistent scalability challenge in development policy and practice: STEs can scale-up and down to operate at variable spatial scales (Domain 5) while maintaining and enhancing connectivity across scales, furthering cost effectiveness and expanding positive impacts.

There are six levels of capacity for each sector, with information resources at the core of each (forming pentagons). Sectors integrate capacities at each level (e.g. Level \#2: Education and training across energy, water, food etc.), and connect via Level \#3: Information resource core. Local and sub-region scale networks can be linked and scaled-up to regional and national scales.

\subsection{Integrators}

Constructive engagement with the diversity of stakeholders (Domain 4) across 
Table 1. Six levels of socio-technical capacity for UD/UP/UDP work. Shows examples of operational components for each level.

\begin{tabular}{ll}
\hline Level & Component \\
\hline & Political seed capital-Diverse stakeholders mobilize sufficient political support for the project, including for the STE
\end{tabular}

- Political seed capital-Diverse stakeholders mobilize sufficient political support for the project, including for the STE approach to urban innovation. The support of local-, regional- and national-level policy makers is important, and this may be stimulated by a show of support from other stakeholders in civil society, working in concert with community based organizations and/or NGOs, and business leaders. Conservatives in government who are slow to innovate may see that their political interests are best served by supporting the urban innovation effort, especially when it tackles pressing economic, social and environmental issues. International NGOs, business philanthropists, and progressive universities are in a strong position 1. Political and to help garner this essential capital. The multi-sector approach has the potential to garner broad-based political support. Financial Seed - Financial seed capital-Diverse stakeholders work together to garner seed finance/funding for pilot projects and Capital demonstration projects that can be used to leverage ongoing investment. Private-public partnerships can work well here provided they also work closely with other stakeholders—esp. civil society groups and marginalized groups—and are invested in the collective STE approach. Source of seed funding include government agencies, multi-lateral development agencies, aid organizations, private-sector donors-and the preference is for a diversified funding stream that will provide stable funding until enterprise activities (Level \#6) and economic energy can step-in to replace it. Reliance on one source only is not desirable. The multi-sector approach has the potential to garner diverse funding support for constituent sectors/issues. Many funding sources do seem to be seeking integrative projects with strong stakeholder partnerships.

2. Human - K-12 programs and curricula that encourage sustainability principles and ways of thinking and doing in the lives of children, families and communities.

resources, education and training, awareness- graduate levels.

raising

- Awareness-raising activities in popular media (TV, radio, social media) that promote innovative ways of thinking about cities, and constructively challenge conventional, business-as-usual modes and ideas.

- Creation of multi-stakeholder, shared knowledge resources using co-generation modes. Mobilization and integration of diverse data, information and knowledge types: indigenous; experiential; narrative (oral histories, storying); video/photographic;

3. Information qualitative; geo-spatial/remotely-sensed; quantitative; modeling and computer-generated scenarios. The form of this resource and knowledge may vary according to the setting and scales to be considered, but a very promising platform for this resource is cloud-based resources mapping. For example, stakeholders co-generate a web-based Health \& Sustainability Atlas (see 4.3) of social, economic and environmental indicators and conditions. The Atlas is populated by diverse data that are processed and integrated by academic researchers who act as gatekeepers, and QC/QA checkers.

- Policy formulation is informed by the information resource in Level \#3, and serves as a response to a set of needs and priorities that emerge from the STE approach

- Among the policy instruments are regulations that encourage sustainable UD/UP/UDP work and discourage un-sustainable policies and practices. Alongside regulations it is necessary to consider incentives that reward compliance

4. Policy mak- (e.g. tax rebates for renewable energies), as well as penalties that exact costs. Having responsive UD legislation and regulations ing, decision is only half of the picture; capacity must also be built to verify compliance and monitor the performance of projects making and (feeding back into the information resource of Level \#3).

governance - Governance-the action or manner of governing, exercising control-is often the focus of development innovation, but when over-emphasized as a matter of power/influence, it can become an end in itself (exerting control) instead of a means to an end (more sustainable cities and regions). STE approaches use transparent, more equitable and accountable modes of governance and decision making, for example the use of integrative, more equitable and transparent approaches to Environmental Impact Assessment (EIA). The ethos of a STE approach is that power/influence is more equitably distributed to serve the social good.

- This level can be thought of as the 'hardware' of UD/UP/UDP work, in the form of manufactured capital: roads, bridges,

5. Appropriate tunnels, railroals, light rail, airports, ports, pipelines, buildings (residential, commercial, industrial, agricultural), energy and technologies and infrastructure power systems of generation and transmission etc. In development work, there has long been a push to think of the 'appropriateness' of the technology choice in terms of accessibility, affordability, cultural sensitivity and 'sustainability'/longevity. These criteria still apply to an integrative STE approach, but the integrative lens on sustainability and climate resilience offers new ways to conceptualize, design and assess the impacts of alternatives.

- Stimulation of the local and regional provision of key products that constitute and support more sustainable urban solutions (e.g. local/regional manufacturing and installation of solar panels, windmills, wave-power devices). This allows for economic sustainability and the replacement of seed finance and investment from Level \#1, and explicitly connects social, economic and 6. Enterprise environmental aspects of sustainability together such that they are inter-dependent and reinforcing of each other.

development - Likewise for enabling services, e.g. research and information generation, investment stimuli, management services, monitoring and evaluation services throughout project stages (Figure 1). There are many services related to education and the knowledge economy of the $21^{\text {st }}$ Century that are integral to all six of these STE capacity levels (e.g. education), and also to the consideration of the six domains of the integrative frame (see 3.0). 


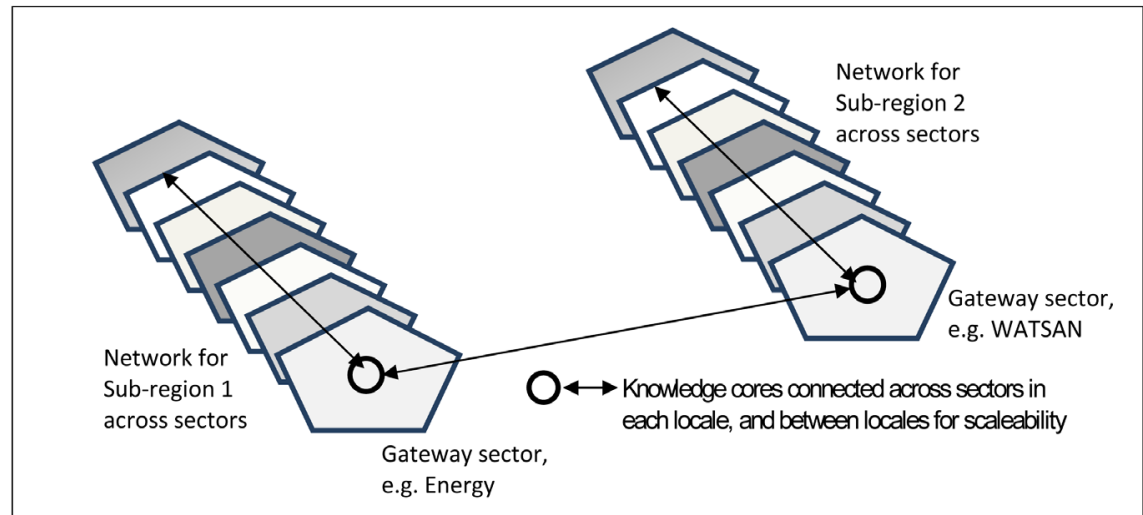

Figure 2. Capacity-building enterprise as a scaleable socio-technical network. There are six levels of capacity for each sector, with information resources at the core of each (forming pentagons). Sectors integrate capacities at each level (e.g. Level 2: education and training across energy, water, food etc.), and connect via Level 3: the information resource core. Local and sub-region scale networks can be linked and scaled-up to regional and national scales.

sectors/issues (Domain 2) and scales (Domain 3) is a challenging endeavor that requires investment in, and training of dedicated Urban Sustainability Integrators. Accordingly, in project proposals it is appropriate to allocate adequate funding to these human resources. Since this role appears governing for integrative STE work, it seems to call for a new type of NGO to play it, whose mission is socio-technical integration (as opposed to the normal narrow topical mission), bolstered by technical and training support from the university sector.

\subsection{Pilot Demonstration Projects}

To energize and sustain the buy-in of stakeholders it is important to use seed funding to create pilot demonstration projects that exemplify UD/UP/UDP innovation, addressing urgent, accessible issues on a short-term planning horizon. Such pilots seek to exemplify the overall STE approach as being responsive to local concerns, and they also serve to adapt the approach to local conditions. An example might be to design and deploy an innovative renewable energy pilot (e.g. green housing), or a water conservation pilot, or a neighborhood health clinic that local stakeholders conceive and help implement. Another initiative that can be galvanizing is to pilot the creation of a participatory Health \& Sustainability Atlas-populated by stakeholder-provided data, and administered/ managed by a university - that tracks existing health outcomes, their social and environmental determinants, healthcare infrastructure, and other sectoral/topical data (including images and photos). This is a scalable demonstrator for the larger STE network.

\section{Case Study: Greater Mexico City/Central Mexico Urban Region}

We demonstrate the hypothetical utility of the integrative, STE approach by ap- 
plying it to one of the most challenging urban contexts in the world: Greater Mexico City in the Central Mexico Urban Region. The conundrums in this context are classic examples: 1) socio-ecological complexity is very high in coupled urban economies and hydrological basins; 2) overlapping spatial scales and temporal dynamics confound traditional fragmented approaches, and call for responses that tackle the conundrum, and do not ignore it; and 3) stakeholder diversity is very high, within a strongly hierarchical, stratified socio-political and economic system characterized by extreme power, widespread systemic corruption, and wealth inequities [60]. Notwithstanding these complexities, pilot work 1998-2000 in three cities-Ciudad Juárez, Chihuahua (1.3 M people in 2010); Atizapán de Zaragoza, Greater Mexico City (0.49M in 2010); and Mérida, Yucatán $(0.78 \mathrm{M}$ in 2010$)$ - using an early STE approach centered on sustainable WATSAN proved viable [26], and informs ongoing efforts.

Turning to the 6-D frame, Domain 1 conceptualizes the challenges of the region in terms of sustainable development principles and climate-change resilience, and frames the response in terms of opportunities for socio-technical enterprise development. Domain 2 helps us to contemplate multiple sectors, topics and issues, and the interconnections among them in terms of stocks and flows of material and energy, and natural, human, social, financial and manufactured capital-i.e. as an integrated urban/regional systems model. Domain 3 illuminates the need to zoom-in and zoom-out to encompass spatial scales appropriate for the socio-ecological setting; a regional, multi-city, multi-watershed scale is essential. Figure 3 is a composite satellite image showing the location of Greater Mexico City (population 21.2 M in 2014, [61]), and the neighboring cities of Pachuca (0.26 M in 2010, [62]), Puebla (1.43 M in 2010, [62]), Cuernavaca-Cuautla (0.49 $\mathrm{M}$ in 2010, [62]), and Toluca (0.49 $\mathrm{M}$ in 2010, [62]). Total urban regional population in 2010 was about $24 \mathrm{M}$. These cities are strongly interconnected in ways Domain 2 calls out, and their interdependency will increase [63] [64]. The strongest socio-ecological interdependencies reside in water supply/hydrology and climate-change, with Greater Mexico City relying strongly on the transfer of water from Río Lerma and Río Cutzamala watersheds to the west, watersheds also exploited by Toluca and its peri-urban and rural populations [60] [65].

The water sector and wastewater sanitation sector (WATSAN) is of primary importance in the context of regional urban sustainability, urban metabolism, and climate change scenarios: it is both a gateway and keystone sector (3.2). Changing climate is increasing the frequency and magnitude of episodic rainfall and flooding, projected to worsen [60] [66]; there is an urgent need to upgrade wastewater/stormwater systems, and increase resilience to flooding. The existing drainage system is old and grossly under-sized, comprising a combined

"'Greater Mexico City" is also called the "Mexico City Metropolitan Area" (MCMA) comprising a total of 77 municipalities, including the core Federal District (16 delegations, officially called "Mexico City" since 2016). 


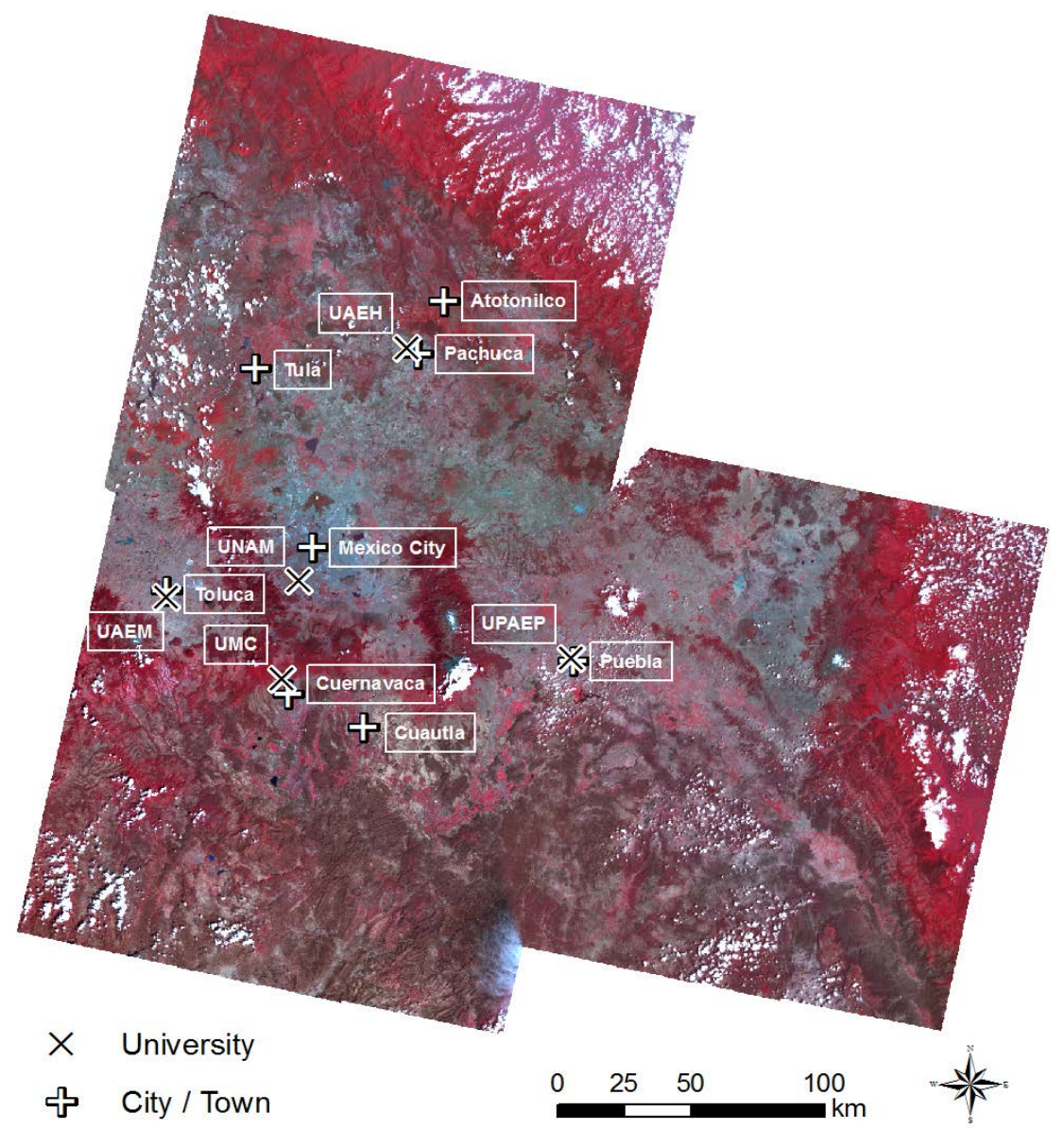

Figure 3. Satellite Image of Mexico City Region, 2015. Shows a spatial scale that includes Mexico City, Pachuca, Toluca, Puebla and Cuernavaca-Cuautla. Comparing imagery from 2000 and 2015, we estimate the land use/land cover change 2000 vs 2015 from nonurban to urban is about $5.5 \%$, less than expected $\left(2560 \mathrm{~km}^{2}\right.$ vs $2700 \mathrm{~km}^{2}$ respectively). This warrants "ground-truthing", but could be explained by a combination of existing urban areas becoming more population-dense where feasible, but also-in the case of the Mexico City Metropolitan Area-that the 34 additional municipalities included since 2000 do not show up as "urban", rather are peri-urban low-density sprawl. Also shows key university locations that can serves as nodes in the recommended regional-scale STE network, and the location of the Atotonilco Wastewater Treatment Plant. By 2020, a new MCMA airport will occupy about $5000 \mathrm{Ha}$ of the dry lake bed of Texcoco, east of Mexico City center. [Image by John Rogan, Zhiwen Zhu and Arthur Elmes, Clark University. Source data: Landsat-5 and Landsat-8 images downloaded from http://glovis.usgs.gov/]. Key: UNAM ((Universidad Nacional Autónoma de México), Mexico City; UAEM (Universidad Autónoma del Estado de México), Toluca; UAEH (Universidad Autónoma del Estado de Hidalgo), Pachuca; UPAEP (Universidad Popular Autónoma del Estado de Puebla), Puebla; UMC (Universidad Morelos de Cuernavaca), Cuernavaca.

wastewater/stormwater system of pipes and channels under slow gravity flow ${ }^{5}$; and there is no combined sewer overflow (CSO) common to US cities because

${ }^{5}$ Overexploitation of aquifers in Greater Mexico City have caused ground subsidence that is compromising the drainage gradient, exacerbating stormwater evacuation-emphasizing the need for integrated WATSAN design. 
there is still no adequate, formal Mexico City-based wastewater treatment system. This means flooding is/will be by a hazardous, highly mobile "soup" of untreated wastewater and stormwater-signaling major health risks from exposure to unchecked pathogens and toxic chemicals. WATSAN, Health and Climate Change are convergent priority sectors/issues.

In 2016, a very large anaerobic-digestion wastewater treatment plant (WWTP) went online: Atotonilco WWTP (Figure 1 for location) has a design capacity of $50 \mathrm{~m}^{3} / \mathrm{s}$, and will treat about $60 \%$ of Greater Mexico City wastewater, up from only $10 \%$ previously [65]. However, while sanitation gains are significant, the plant's location at the end of drainage channels is confounding, about 70 miles down-gradient from the city: this precludes valuable treatment and reuse to reduce water supply stress in the city [60] [64]. One way forward would be to consider a network of smaller city-based WWTPs to handle, pre-treat, treat and recycle the projected increased volume flow of wastewater/stormwater-in conjunction with Atotonilco; the latter could be used as a major component of a regional-scale WATSAN system to serve both Mexico City and Pachuca (Figure 3). A 6-D/STE perspective allows that vision to materialize in thought and deed, whereas a business-as-usual approach obscures and blocks it.

Considering Domains 4 and 5, on the assets side, stakeholder diversity in terms of knowledge types and capacities is high, and the STE approach has been shown to be able to transform destructive relationships and interactions into constructive ones and even to mitigate corruption [26]. Domain 6 is a way to not only incorporate socio-technical capacity mobilization/strengthening into the UD/UP/UDP process, but to make it a centerpiece with positive stakeholder incentives that outweigh costs. Domains 4-6 come together when we conceive of societal response in terms of neighborhood, city and regional scale knowledge/capacity networks (Figure 2). Universities in each of the five cities (Figure 3 for locations by city) have a special role in STE: linked together they are equipped to provide integrating "architecture" for the STE network, enjoying an enhanced yet traditional role as educators of UD/UP/UDP/sustainable development practitioners, and researchers who co-generate the core shared knowledge/information resource (Figure 2) with other stakeholders.

\section{Conclusion}

The challenges for $21^{\text {st }}$ Century urban design, urban planning and urban development practice (UD/UP/UDP) are substantial, many and varied, especially in an unstable climate-changing world. In the face of them, business-as-usual approaches to practice and professional training fall far short, tending to be fragmented and tilted strongly to technology and manufactured capital. At the same time, sustainability theory, practice and empirical evidence are teaching us that investments in human and social capital through knowledge/capacity networks offer a higher probability of success-with technology playing a vital enabling and supporting role. The 6-D integrative lens encourages a new perspective to 
illuminate UD/UP/UDP work and re-imagine it as a socio-technical enterprise (STE). The Mexico City/Central Mexico Urban Region case suggests the power this approach has to re-frame pressing urban challenges under climate-change scenarios as STE opportunities, to understand them more fully as socio-ecological/manufactured systems, and to re-imagine our collective socio-technical responses to them. This approach has major implications for $\mathrm{UD} / \mathrm{UP} / \mathrm{UDP}$ education and training, the role of the University as enabler and catalyst, innovations to professional practice, as well as urban development policy on local, regional and global scales.

\section{Acknowledgements}

Thanks to Kathryn J. Madden at Clark University for providing insights and literature on the state of urban design.

\section{Note}

The author's first degree was a Bachelor of Science (BSc.) in Civil Engineering from Loughborough University in 1984. BSc., M.S. (1990) and D.Env. (1998) degrees and ongoing scholar-practitioner work are linked by a common water/health/sustainability theme.

\section{References}

[1] UNPFA (2007) State of the World Population 2007. UN Population Fund. https://www.unfpa.org/publications/state-world-population-2007

[2] IPCC (2014) Climate Change 2014: Synthesis Report. In: Core Writing Team, Pachauri, R.K. and Meyer, L.A., Eds., Contribution of Working Groups I, II and III to the Fifth Assessment Report of the Intergovernmental Panel on Climate Change, Intergovernmental Panel on Climate Change (IPCC), Geneva, $151 \mathrm{p}$.

[3] WCED (1987) Our Common Future. World Commission of Environment and Development (WCED) United Nations.

http://www.un-documents.net/our-common-future.pdf

[4] UN/DESA (2016) Back to Our Common Future. Sustainable Development in the 21st Century (SD21) Project.

https://sustainabledevelopment.un.org/content/documents/UN-DESA_Back_Com mon_Future_En.pdf

[5] Carr, E.R. (2008) The Millennium Village Project and African Development: Problems and Potentials. Progress in Development Studies, 8, 333-344. https://doi.org/10.1177/146499340800800403

[6] Downs, T.J., Carr, E. and Goble, R. (2017) Addressing Risk Conundrums in Sustainable Development. In: Kasperson, R., Ed., Risk Conundrums. Solving Unsolvable Problems, Earthscan/Routledge, Oxford, 276 p.

[7] Krieger, A. (2006) Where and How Does Urban Design Happen? In the Origins and Evolution of Urban Design, 1956-2006. Harvard Design Magazine, Spring/Summer 2006.

[8] Ryan, B. (2012) Rightsizing Shrinking Cities: The Urban Design Dimension. In: Dewar, M. and Manning Thomas, J., Eds., The City after Abandonment, University 
of Pennsylvania Press, Philadelphia, 400 p.

[9] Ryberg-Webster, S. and Kinahan, K.L. (2014) Historic Preservation and Urban Revitalization in the Twenty-First Century. Journal of Planning Literature, 29, 119-139. https://doi.org/10.1177/0885412213510524

[10] Brookings (1998) Brookings Institution Center on Urban and Metropolitan Policy and Fannie Mae Foundation. A Rise in Downtown Living. http://www.brookings.edu/research/reports/1998/11/downtown

[11] Sohmer, R. and Lang, R.E. (1998) Beyond This Old House: Historic Preservation in Community Development. Housing Policy Debate, 9, 425-430. https://doi.org/10.1080/10511482.1998.9521302

[12] Birch, E.L. (2002) Having a Longer View on Downtown Living. Journal of the American Planning Association, 68, 5-21. https://doi.org/10.1080/01944360208977188

[13] Birch, E.L. (2005) Who Lives Downtown? Brookings Institution, Metropolitan Policy Program, Washington DC.

[14] Birch, E.L. (2007) Hopeful Signs: U.S. Urban Revitalization in the Twenty-First Century. In: Ingram, G.K. and Hung Hong, Y., Eds., Land Policies and Their Outcomes, Lincoln Institute of Land Policy, Cambridge, 286-329.

[15] Vey, J.S. (2007) Restoring Prosperity: The State Role in Revitalizing America's Older Industrial Cities. Brookings Institution Metropolitan Policy Program, Washington DC.

[16] Piiparinen, R. (2013) Mapping Human Capital: Where Northeast Ohio's Young and Middle-Age Adults Are Locating. Briefly Stated No. 13-02, Center on Urban Poverty and Community Development, Mandel School of Applied Social Sciences, Case Western Reserve University, Cleveland.

[17] Keating, W.D. and Krumholz, N. (1991) Downtown Plans of the 1980s: The Case for More Equity in the 1990s. Journal of the American Planning Association, 57, 136-152. https://doi.org/10.1080/01944369108975483

[18] Robertson, K.A. (1995) Downtown Redevelopment Strategies in the United States: An End-of-the-Century Assessment. Journal of the American Planning Association, 61, 429-437. https://doi.org/10.1080/01944369508975655

[19] Leinberger, C.B. (2005) Turning around Downtown: Twelve Steps to Revitalization. Brookings Institution Center on Urban and Metropolitan Policy, Washington DC.

[20] Birch, E.L. (2009) Downtown in the New American City. Annals of the American Academy of Political and Social Science, 626, 134-153. https://doi.org/10.1177/0002716209344169

[21] Strom, E. (2008) Rethinking the Politics of Downtown Development. Journal of Urban Affairs, 30, 37-61. https://doi.org/10.1111/j.1467-9906.2007.00373.x

[22] Allianz, S.E. (2015) The Megacity of the Future Is Smart. https://allianz.com/oneweb/cms/www.allianz.com/en/press/news/studies/151130_th e-megacity-of-the-future-is-smart/

[23] c2 (2018) Einstein Principle. http://wiki.c2.com/?EinsteinPrinciple

[24] UNGA UN General Assembly (2014) The Road to Dignity by 2030: Ending Poverty, Transforming All Lives and Protecting the Planet. Synthesis Report of the Secretary-General on the Post-2015 Sustainable Development Agenda. https://sustainabledevelopment.un.org/majorgroups/post2015/synthesisreport

[25] Downs, T.J. (2007) A Systematic Integrated Approach for Crafting Poverty Reduc- 
tion and Sustainable Development Projects Natural Resources Forum-United Nations. Sustainable Development Journal, 31, 35-50.

[26] Downs, T.J. (2001) Making Sustainable Development Operational: Integrated Capacity Building for the Water Supply and Sanitation Sector in Mexico. Journal of Environmental Planning and Management, 44, 525-544. https://doi.org/10.1080/09640560120060948

[27] Brown, M.E., Antle, J.M., Backlund, P., Carr, E.R., Easterling, W.E., Walsh, M.K., Ammann, C., Attavanich, W., Barrett, C.B., Bellemare, M.F., Dancheck, V., Funk, C., Grace, K., Ingram, J.S.I., Jiang, H., Maletta, H., Mata, T., Murray, A., Ngugi, M., Ojima, D., O’Neill, B. and Tebaldi, C. (2015) Climate Change, Global Food Security, and the U.S. Food System. United States Department of Agriculture, Washington DC, $146 \mathrm{p}$.

[28] USAID (2014) Climate-Resilient Development: A Framework for Understanding and Addressing Climate Change. Global Climate Change Office, United States Agency for International Development, Washington DC.

[29] Roncoli, C., Ingram, K. and Kirshen, P. (2002) Reading the Rains: Local Knowledge and Rainfall Forecasting in Burkina Faso. Society \& Natural Resources, 15, 409-427. https://doi.org/10.1080/08941920252866774

[30] Davis, D.K. (2005) Indigenous Knowledge and the Desertification Debate: Problematising Expert Knowledge in North Africa. Geoforum, 36, 509-524. https://doi.org/10.1016/j.geoforum.2004.08.003

[31] Mercer, J., Kelman, I., Taranis, L. and Suchet-Pearson, S. (2010) Framework for Integrating Indigenous and Scientific Knowledge for Disaster Risk Reduction. Disas ters, 34, 214-239. https://doi.org/10.1111/j.1467-7717.2009.01126.x

[32] Carr, E.R. (2011) Delivering Development: Globalization's Shoreline and the Road to a Sustainable Future. Palgrave Macmillan, New York. https://doi.org/10.1057/9780230319974

[33] Mitchell, T. (2002) Rule of Experts: Egypt, Techno-Politics, Modernity. University of California Press, Oakland.

[34] Escobar, A. (1995) Encountering Development. Princeton University Press, Princeton.

[35] Ferguson, J. (1994) The Anti-Politics Machine: Development, Depoliticization, and Bureaucratic Power in Lesotho. University of Minnesota Press, Minneapolis.

[36] Geels, F.W. (2010) Ontologies, Socio-Technical Transitions (to Sustainability), and the Multi-Level Perspective. Research Policy, 39, 495-510. https://doi.org/10.1016/j.respol.2010.01.022

[37] Kates, R.W., Clark, W.C., Corell, R., Michael Hall, J., Jaeger, C.C., Lowe, I., McCarthy, J.J., et al. (2001) Sustainability Science. Science, 292, 641-642. http://science.sciencemag.org/content/292/5517/641 https://doi.org/10.1126/science.1059386

[38] Downs, T.J. (2008) Transforming Impact Assessment for Sustainable Development and Poverty Eradication. Engineering Sustainability, 116, 39-54. https://doi.org/10.1680/ensu.2008.161.1.39

[39] USAID (2012) Building Resilience to Recurrent Crisis: USAID Policy and Program Guidance. United States Agency for International Development, Washington DC.

[40] Time (2018) Cape Town Is 90 Days away from Running out of Water. http://time.com/5103259/cape-town-water-crisis/ 
[41] Turner, B.L., Clark, W.C., Kates, R.W., Richards, J.F. and Mathews, J.T. (1993) The Earth as Transformed by Human Action. Cambridge University Press, Cambridge.

[42] Carr, E.R. (2014) Assessing Mali’s Direction National de La Metéorologie Agrometeorological Advisory Program: Preliminary Report on the Climate Science and Farmer Use. United States Agency for International Development, Washington DC.

[43] Carr, E.R. (2013) Livelihoods as Intimate Government: Reframing the Logic of Livelihoods for Development. Third World Quarterly, 34, 77-108. https://doi.org/10.1080/01436597.2012.755012

[44] Chambers, R. (1995) Rural Development: Putting the Last First. Addison-Wesley Publishing Co., Harlow.

[45] Chambers, R. (1997) Whose Reality Counts? Putting the First Last. Intermediate Technology, London. https://doi.org/10.3362/9781780440453

[46] Chambers, R. (2008) Revolutions in Development Inquiry. Earthscan, London.

[47] Chhotray, V. (2004) The Negation of Politics in Participatory Development. Development and Change, 35, 327-352. https://doi.org/10.1111/j.1467-7660.2004.00354.x

[48] Kapoor, I. (2002) The Devil's in the Theory: A Critical Assessment of Robert Chambers' Work on Participatory Development. Third World Quarterly, 23, 101-117. https://doi.org/10.1080/01436590220108199

[49] Cornwall, A. (2003) Whose Voices? Whose Choices? Reflections on Gender and Participatory Development. World Development, 31, 1325-1342. https://doi.org/10.1016/S0305-750X(03)00086-X

[50] Cornwall, A. (2008) Unpacking "Participation": Models, Meanings and Practices. Community Development Journal, 43, 269-283. https://doi.org/10.1093/cdj/bsn010

[51] Leal, P.A. (2007) Participation: The Ascendancy of a Buzzword in the Neo-Liberal Era. Development in Practice, 17, 539-548. https://doi.org/10.1080/09614520701469518

[52] Holling, C.S. (1978) Adaptive Environmental Assessment and Management. Wiley, Chichester, $377 \mathrm{p}$.

[53] Walker, B., Holling, C.S., Carpenter, S.R. and Kinzig, A. (2004) Resilience, Adaptability and Transformability in Social-Ecological Systems. Ecology and Society, 9, 5. http://www.ecologyandsociety.org/vol9/iss2/art5 https://doi.org/10.5751/ES-00650-090205

[54] Berkes, F., Colding, J. and Folke, C. (2000) Rediscovery of Traditional Ecological Knowledge as Adaptive Management. Ecological Applications, 10, 1251-1262. https://doi.org/10.1890/1051-0761(2000)010[1251:ROTEKA]2.0.CO;2

[55] Kasperson, R.E., Golding, D. and Tuler, S. (1992) Social Distrust as a Factor in Siting Hazardous Facilities and Communicating Risks. Journal of Social Issues, 48, 161-187. https://doi.org/10.1111/j.1540-4560.1992.tb01950.x

[56] Slovic, P. (1993) Perceived Risk, Trust, and Democracy. Risk Analysis, 13, 675-682. https://doi.org/10.1111/j.1539-6924.1993.tb01329.x

[57] Schnackenberg, A.K. and Tomlinson, E.C. (2014) Organizational Transparency: A New Perspective on Managing Trust in Organization-Stakeholder Relationships. Journal of Management, 42, 1784-1810.

[58] Costanza, R., de Groot, R., Sutton, P., van der Ploeg, S. Anderson, S.J., Kubiszewski, I., Farber, S. and Kerry Turner, R. (2014) Changes in the Global Value of Ecosystem Services. Global Environmental Change, 26, 152-158. https://doi.org/10.1016/j.gloenvcha.2014.04.002 
[59] Griggs, D., Stafford-Smith, M., Gaffney, O., Rockström, M.C., Shyamsundar, P., Steffen, W., Glaser, G., Kanie, N. and Noble, I. (2013) Sustainable Development Goals for People and Planet: Commentary. Nature, 495, 305-307. https://doi.org/10.1038/495305a

[60] Downs, T.J. and Mazari-Hiriart, M. (2017) Addressing Risk Conundrums in Megacity Development: Mexico City. In: Kasperson, R., Ed., Risk Conundrums: Solving Unsolvable Problems, Earthscan/Routledge, Oxford, 276 p.

[61] WPR (2016) World Population Review. http://worldpopulationreview.com/world-cities/mexico-city-population/

[62] INEGI (2010) Censo de Población y Vivienda 2010. Instituto Nacional de Estadística, Geografía e Informática. Mexico City, Mexico.

[63] Bojórquez-Tapia, L.A., Luna-Gonzalez, L., Cruz-Bello, G.M., Gómez-Priego, P., Juárez-Marusich, L. and Rosas-Pérez, I. (2011) Regional Environmental Assessment for Multiagency Policy Making: Implementing an Environmental Ontology through GIS-MCDA. Environment and Planning B: Planning and Design, 38, 539-563. https://doi.org/10.1068/b36129

[64] Bojórquez-Tapia, L.A., Cruz-Bello, G.M. and Luna-Gonzalez, L. (2013) Connotative Land Degradation Mapping: A Knowledge-Based Approach to Land Degradation Assessment. Environmental Modelling and Software, 40, 51-64. https://doi.org/10.1016/j.envsoft.2012.07.009

[65] Downs, T.J., Mazari-Hiriart, M., Domínguez-Mora, R. and Suffet, I.H. (2000) Sustainability of Least-Cost Policies to Meet Mexico City's Future Water Demand. Water Resources Research, 36, 2321-2339. https://doi.org/10.1029/1999WR900234

[66] World Bank (2016) Climate Change Portal. Risk Screening Overview. http://sdwebx.worldbank.org/climateportalb/home.cfm?page=country_profile\&CC ode=MEX\&ThisTab=Dashboard 